\title{
Two new records of the resupinate polypore fungi, Ceriporia cystidiata and Macrohyporia dictyopora, in Thailand
}

\author{
Ponlada Permpornsakul $^{\mathrm{a}}$, Sehanat Prasongsuk ${ }^{\mathrm{a}}$, Pongtharin Lotrakul ${ }^{\mathrm{a}}$, Douglas E. Eveleigh ${ }^{\mathrm{b}}$, \\ Donald Y. Kobayashi ${ }^{c}$, Sheng Hua $\mathrm{Wu}^{\mathrm{d}}$, Tsuyoshi Imai ${ }^{\mathrm{e}}$, Hunsa Punnapayak ${ }^{\mathrm{a}, *}$ \\ a Plant Biomass Utilization Research Unit, Department of Botany, Faculty of Science, \\ Chulalongkorn University, Bangkok 10330 Thailand \\ b Department of Biochemistry and Microbiology, School of Environmental and Biological Science, \\ Rutgers University, New Brunswick, New Jersey 08903, USA \\ c Department of Plant Biology and Pathology School of Environmental and Biological Science, \\ Rutgers University, New Brunswick, New Jersey 08901, USA \\ d Department of Botany, National Museum of Natural Science, Taichung 404, Taiwan \\ e Division of Environmental Science and Engineering, Graduate School of Science and Engineering, \\ Yamaguchi University, Ube, Yamaguchi, 755-8611, Japan
}

*Corresponding author, e-mail: phunsa@chula.ac.th

Received 23 Jun 2015

Accepted 21 Jun 2016

\begin{abstract}
Wood-inhabiting resupinate polypore fungi are abundant and widely distributed in tropical forests of Thailand. In our survey, Ceriporia cystidiata and Macrohyporia dictyopora were found in Thailand for the first time. Identification was based on morphological characteristics and DNA sequences of internal transcribed spacers and large subunit (LSU) nuclear ribosomal RNA genes. The initial phylogenetic analyses showed that $C$. cystidiata clustered as a sister clade to $C$. lacerata, and $M$. dictyopora was placed firmly in the phlebioid clade.
\end{abstract}

KEYWORDS: molecular phylogeny, taxonomy, tropics

\section{INTRODUCTION}

Resupinate fungi refer to basidiomycetes that have flattened fruiting bodies developed on or under wood surfaces ${ }^{1,2}$. They resemble each other in gross morphology, but possess diverse anatomical, physiological, and molecular characteristics ${ }^{3,4}$. These fungi are widely represented in tropical forests as efficient wood decomposers. To date, there are up to 1853 resupinate polypore species in 282 genera within 50 putative families: 766 species are reported in Asia ${ }^{5-11}$. Recently, comprehensive studies on wood-rotting fungi in tropical areas of southern China have been completed, and many new species have been described ${ }^{5-8}$. Taxonomic and systematic studies of the resupinate fungi have been performed mostly based upon their morphology since their molecular data, especially the information from tropic regions is limited ${ }^{3,9,10}$.

The genus Ceriporia Donk (Phanerochaetaceae, Polyporales) of wood-inhabiting Polyporales was characterized by producing resupinate basidio- mata with various colours, causing a white rot, and having cylindrical to oblong-ellipsoid basidiospores $^{12-15}$. About 36 species of Ceriporia have been morphologically identified but only a few of them were described with molecular support ${ }^{13}$. Although a phylogeny study could place this genus in phlebioid clade of polypore group, it is not monophyletic $^{13}$.

Macrohyporia Johan. \& Ryv. (Polyporaceae, Polyporales) is recorded in Africa, Argentina, Australia, and New Zealand ${ }^{16-19}$. The morphological markers of this genus are very broad ( $>6 \mu \mathrm{m}$ diameter) generative hyphae, refractive thickened walls of binding hyphae, and thin-walled subglobose basidiospore $^{16}$. There are currently only two known species namely $M$. pileata and $M$. dictyopora ${ }^{17}$. Molecular biological data do not appear to have been reported ${ }^{9}$. M. dictyopora is the type species of the genus Macrohyporia. However, it differs from $M$. pileata in having resupinate basidiomata ${ }^{17-20}$.

Wood-inhabiting Homobasidiomycetes in Thailand have been extensively studied. About 2000 
species have been described ${ }^{21,22}$, about 190 of which are resupinate polypore fungi which includes 6 new species for Asia and 9 species have only been reported in SE Asia ${ }^{11,23}$. During a survey of resupinate fungi in Thailand, two previously unknown species were found. Hence this study contributes further information of new resupinate polypore species for Thailand. Their morphological description, sequences of internal transcribed spacer (ITS) and nuclear ribosomal large subunit (nLSU) are outlined and the evolutionary relationships of this interesting group of wood-inhabiting fungi are discussed.

\section{MATERIALS AND METHODS}

\section{Morphological observation}

Basidiomata of resupinate fungi were collected from tropical forests around Thailand. The specimens were dried and deposited in the herbarium of the Plant Biomass Utilization Research Unit, Department of Botany, Faculty of Science, Chulalongkorn University, Thailand, and specimen codes were assigned. Species identification of the resupinate fungi samples was performed using the standard morphological criteria ${ }^{12,24,25}$. Macromorphological characteristics of the hymenial surface were observed using fresh specimens. Micromorphological characterization and drawings were made from slide preparations by free-hand section of dried specimens mounted with $5 \% \mathrm{KOH}$ and stained with phloxine, cotton blue, and Melzer's solutions under light microscopy. Microscopic structures, including the basidiospores $(\mathrm{Q}$; length/width ratio), hyphae, and cystidia, were measured using an ocular micrometre under light microscope.

\section{DNA extraction, amplification, and sequencing}

Mycelia of each fungal sample growing on the top of cellophane membranes placed on $2 \%(\mathrm{w} / \mathrm{v})$ malt extract agar were harvested after $7 \mathrm{~d}$ of inoculation. Their genomic DNA was isolated by standard phenol-chloroform extraction ${ }^{26}$. The ITS and LSU regions were amplified using the ITS4/ITS5 and LROR/LR7 primer pairs, respectively ${ }^{27}$. The PCR reactions were performed using Chroma Taq DNA polymerase (Denville Scientific, Metuchen, NJ, USA) in a final volume of $25 \mu \mathrm{l}$. The PCR was thermocycled at $94^{\circ} \mathrm{C}$ for $2 \mathrm{~min}$, followed by $25 \mathrm{cy}$ cles of $94^{\circ} \mathrm{C}$ for $10 \mathrm{~s}, 55^{\circ} \mathrm{C}$ for $30 \mathrm{~s}$, and $72^{\circ} \mathrm{C}$ for $1 \mathrm{~min}$, and subsequently a final $72^{\circ} \mathrm{C}$ for $10 \mathrm{~min}$. The PCR products were purified using a QIAquick PCR Purification Kit (Qiagen, Hilden, Germany) and
Table 1 Taxa used for phylogenetic analysis in this study with and GenBank accession numbers.

\begin{tabular}{|c|c|c|c|}
\hline \multirow[t]{2}{*}{ Species name } & \multirow[t]{2}{*}{ Sample no. } & \multicolumn{2}{|c|}{ GenBank accession no. } \\
\hline & & ITS & nLSU \\
\hline Abortiporus biennis & TFRI 274 & EU232187 & EU232277 \\
\hline Antrodia albida & CBS 308.82 & DQ491414 & AY515348 \\
\hline Ceriporia alachuana & Li 1011 & JX623898 & JX644047 \\
\hline C. alachuana & Li 1115 & JX623900 & JX644050 \\
\hline C. aurantiocarnescens & Yuan 2066 & JX623902 & JX644042 \\
\hline C. aurantiocarnescens & Dai 6055 & JX623904 & JX644043 \\
\hline C. bubalinomarginata & Dai 11327 & JX623953 & JX644045 \\
\hline C. bubalinomarginata & Dai 12499 & JX623954 & JX644043 \\
\hline C. camaresiana & Cui 3238 & JX623931 & JX644060 \\
\hline C. crassitunicata & Dai 10833 & JX623935 & JX644064 \\
\hline C. crassitunicata & Dai9995 & JX623905 & \\
\hline C. cystidiata & PBU 0048 & KC570339 & KU760725 \\
\hline C. excels & Dai 3204 & KF856503 & \\
\hline C. excels & LE247365 & & JX644056 \\
\hline C. inflata & Dai 10376 & JX623929 & JX644062 \\
\hline C. inflata & Cui 7712 & JX623930 & JX644063 \\
\hline C. lacerata & Dai 9501 & JX623908 & JX644069 \\
\hline C. lacerata & Dai 10734 & JX623916 & JX644068 \\
\hline C. lacerata & Cui 7229 & JX623919 & \\
\hline C. lacerata & Dai 10522 & JX623915 & \\
\hline C. mellea & Dai 9453 & JX623932 & JX644059 \\
\hline C. mellea & Dai 9667 & JX623933 & JX644058 \\
\hline C. nanlingensis & Li 1670 & JX623939 & JX644055 \\
\hline C. nanlingensis & Dai 8107 & JX623938 & JX644052 \\
\hline C. pseudocystidiata & Cui 6878 & JX623943 & JX644057 \\
\hline C. purpurea & Dai 6205 & JX623951 & JX644046 \\
\hline C. purpurea & Dai 6366 & JX623952 & JX644047 \\
\hline C. reticulata & Li 1045 & JX623946 & \\
\hline C. reticulata & KHL 11981 & & EU118614 \\
\hline C. spissa & Dai 10477 & KC182769 & KC182781 \\
\hline C. spissa & Yuan 5862 & KC182771 & KC182782 \\
\hline C. sulphuricolor & Dai 6090 & JX623934 & JX644066 \\
\hline C. tarda & Dai 10226 & JX623945 & \\
\hline C. variegata & Li 1780 & JX623936 & JX644065 \\
\hline C. viridans & Yuan 2744 & KC182773 & \\
\hline C. viridans & Cui 8012 & KC182774 & \\
\hline \multicolumn{4}{|l|}{ Ceriporiopsis } \\
\hline alboaurantia & Cui 2877 & KF845954 & KF845947 \\
\hline C. aneirina & Dai 12657 & KF845952 & KF845945 \\
\hline Dacryobolus karstenii & KHL 11162 & EU118624 & EU118624 \\
\hline \multicolumn{4}{|l|}{ Gelatoporia } \\
\hline Gloeoporus taxicola & GL52 & AM231907 & \\
\hline G. taxicola & O 146364 & AM231903 & \\
\hline H. annosum & PFC 5252 & DQ384592 & DQ384592 \\
\hline Junghuhnia nitida & KHL 11903 & EU118638 & EU118638 \\
\hline L. persicinus & DA-41 & EU402566 & EU402533 \\
\hline L. sulphureus & GR-12 & EU402561 & EU402534 \\
\hline M. dictyopora & PBU 0051 & KC570331 & KU760726 \\
\hline \multicolumn{4}{|l|}{ Phanerochaete } \\
\hline chrysosporium & BKM-F-1767 & HQ188436 & GQ470643 \\
\hline P. magnoliae & HHB 9701 & KP135089 & \\
\hline P. magnoliae & HНB 9829 & KP135090 & \\
\hline P. sordida & CY180 & HQ608013 & \\
\hline P. sordida & $\mathrm{T} 8$ & JN253600 & \\
\hline Phlebia livida & FCUG 2189 & AF141624 & AF141624 \\
\hline P. livida & MG104 & HQ153416 & \\
\hline P. livida & MG103 & HQ153415 & \\
\hline P. radiata & ATCC 64658 & FJ746663 & \\
\hline P. tremellosa & BRFM 968 & JX082340 & \\
\hline P. tremellosa & GU062266 & GU062266 & \\
\hline Polyporus tuberaster & CulTENN 8976 & AF516598 & AJ488116 \\
\hline \multicolumn{4}{|l|}{ Steccherinum } \\
\hline & KHL 11905 & EU118668 & EU118668 \\
\hline Trametes pubescens & PRM 900586 & AY684173 & AY855906 \\
\hline Trametopsis cervina & LEBIN2974 & $J X 463662$ & JX463662 \\
\hline $\begin{array}{l}\text { Wolfiporia } \\
\text { dilatohypha }\end{array}$ & FP72162 & KC585401 & KC585236 \\
\hline
\end{tabular}


quantified. A 20 ng sample of each PCR product was sequenced by the dideoxy chain termination method (GENEWIZ DNA Sequencing Service, NJ). The sequences were assembled and analysed using the DNASTAR sequence analysis software (Lasergene, Madison, WI), and manually edited and assembled into contigs using Seqman (DNASTAR, Inc., Madison, WI). All new sequences were submitted to GenBank (Table 1) and screened for homologues against the GenBank database using the BLAST tool (www.ncbi.nlm.nih.gov/blast).

\section{Phylogenetic analysis}

The newly generated ITS and LSU sequences of each species in this study were combined as dataset (ITS+LSU). Each dataset was aligned with the sequences of related taxa downloaded from GenBank (Table 1) using the Muscle algorithm ${ }^{28}$ with default parameters and manually edited in MEGA6 ${ }^{29}$. All characters were equally weighted and gaps were treated as missing data. Maximum parsimony phylogenetic analysis was conducted using PAUP* version $4.0 \mathrm{~b} 10^{30}$. The sequence of Antrodia albida from Antrodia clade was selected as an outgroup for the analysis of C. cystidiata ${ }^{13}$ and Heterobasidion annosum from Russuloid clade was used as an outgroup for the analysis of Macrohyporia dictyopora ${ }^{3}$ (Table 1). Trees were then generated through a heuristic search with TBR branch swapping and 10 random sequence additions. Max-trees were set to 100 branches. Topology stability was assessed by performing 1000 bootstrap replicates. Descriptive tree statistics tree length, consistency index (CI), retention index (RI), and rescaled consistency index (RCI), were calculated for each tree. Bayesian analysis was analysed by MrBayes 3.2.2 and Bayesian posterior probabilities for each clade were presented $^{13,31}$.

\section{RESULTS AND DISCUSSION}

\section{Taxonomic}

\section{C. cystidiata Ryvarden \& Iturr. $2003^{14}$ (Fig. 1)}

Specimen examined: Thailand, Botanical garden of Roi-Et College of Agriculture and Technology, RoiEt Province, on dead wood, coll. P. Permpornsakul, June 2008, PBU 0048.

Distribution: Latin America; Venezuela ${ }^{14}$ and Southeast Asia; Thailand.

Resupinate basidioma, brittle when dry, $1 \mathrm{~mm}$ thick, pore surface white to pale cream, pores thinwalled, round to angular, 6-8 per $\mathrm{mm}$, tube layer concolourous to pore surface, up to $1 \mathrm{~mm}$ deep.

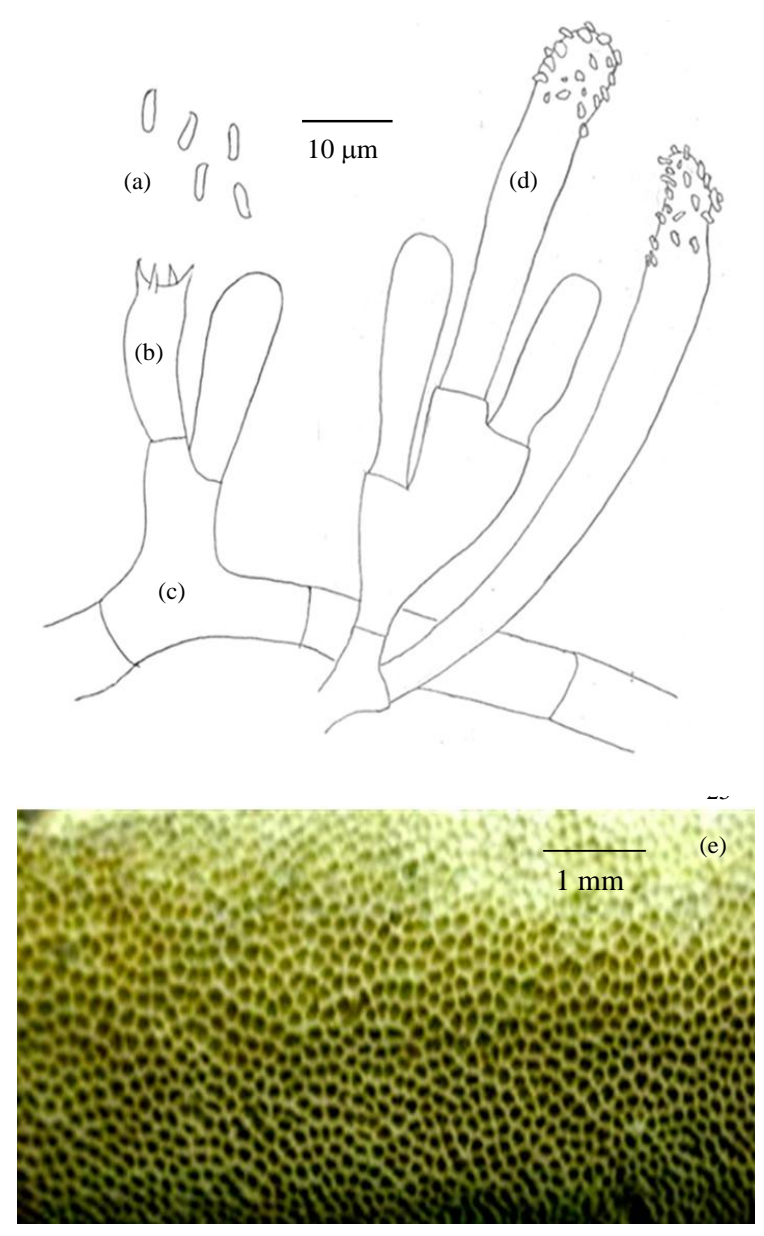

Fig. 1 Ceriporia cystidiata; microscopic features: (a) allantoid basidiospores, (b) basidia, (c) generative hyphae, and (d) tubular apical encrusted cystidia; (e) basidioma.

Subiculum very thin, cottony and whitish. Hyphal system monomitic; generative hyphae hyaline, thin to slightly thick-walled, simple-septate, with sparse branching, negative in Melzer's reagent, 3-8 $\mu \mathrm{m}$ in diameter. Basidia clavate, 4-sterigmate, 10$12 \times 3.5-4.5 \mu \mathrm{m}$, simple-septate at the base. Cystidia present in the hymenium, tubular, thin-walled, with a slight apical encrustation, up to $90 \mu \mathrm{m}$ long, 5-12 $\mu \mathrm{m}$ wide. Basidiospore allantoid $(Q=2.5-$ 2.7; $n=15 / 1$ ), thin-walled, smooth, 4-4.5 $\times 1 \mu \mathrm{m}$, hyaline, and inamyloid.

Notes: The occurrence of $C$. cystidiata was previously only known from the type locality in Venezuela ${ }^{14}$. The $C$. cystidiata differs from another species within Ceriporia in presenting an encrusted cystidia $^{14,15}$. Basidioma of $C$. cystidiata is similar to C. alachuana, C. ferruginicincta, C. lacerata, and C. pseudocystidiata by having a whitish to ochreous 
pore surface. However, it differs from C. alachuana, and $C$. ferruginicincta by pore size and presence of cystidia, also from C. pseudocystidiata by the presence of an apical encrusted cystidia ${ }^{13,14}$. Even the basidiomata of $C$. lacerata, and C. cystidiata are not different, $C$. lacerata can be distinguished from C. cystidiata by its pore size and presence of cystidia since the pore size of $C$. lacerata is larger than that of C. cystidiata, and C. lacerata has some cystidia ${ }^{13,14}$.

\section{M. dictyophora (Cooke) I. Johans. \& Ryvarden, $1979^{18}$ (Fig. 2)}

Specimen examined: One specimen from Thailand, Erawan National Park, Kanchanaburi Province, on dead wood, coll. P. Permpornsakul, June 2008, PBU 0051.

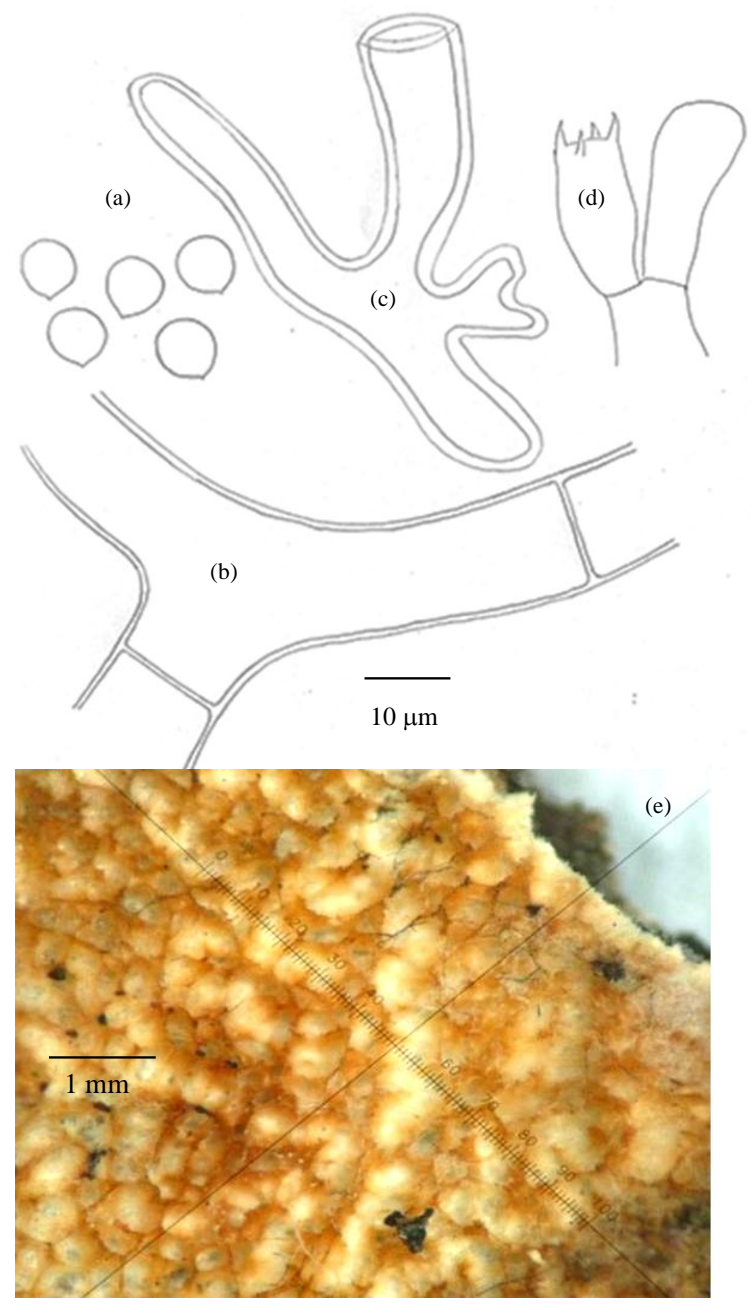

Fig. 2 Macrohyporia dictyopora; microscopic features: (a) subglobose basidiospores, (b) generative hyphae, (c) basidia, and (d) binding hyphae; (e) basidioma odontoid.
Distribution: Australia ${ }^{16,17,32}$, East Africa ${ }^{18,19}$, and Southeast Asia; Thailand.

Resupinate-adnate basidioma, covering large areas, $2-3 \mathrm{~mm}$ thick. Pore surface white to pale brown, margin thin, white, odontoid; 3-4 per mm. Hyphal system dimitic: generative hyphae generally 2-3 thick, up to $10 \mu \mathrm{m}$ in diameter, colourless, simple septate and without clamp-connections; binding hyphae much branched outer wall curved, nearly solid, $1.5-2 \mu \mathrm{m}$ thick, up to $6 \mu \mathrm{m}$ in diameter, colourless. Cystidia absent. Basidia clavate, 12$14 \times 3.5-4 \mu \mathrm{m}$, four-spored. Basidiospore $(Q=1.1-$ $1.3 ; n=13 / 1$ ) subglobose, thick-walled, smooth, $4.5-6 \mu \mathrm{m}$ in diameter, hyaline, and inamyloid.

Note: The hyphal system of Macrohyporia resembles to that of Laetiporus sulphureus and Poria cocos. It is separated from Laetiporus by the basidioma and binding hyphae, also differs from Poria by the spore characteristics ${ }^{33}$. However, the specimen of $M$. dictyopora in this study differs from the previous specimen reported from New Zealand by producing narrower binding hyphae ${ }^{16}$.

\section{Molecular and phylogenetic analysis}

The newly generated ITS and LSU sequences of C. cystidiata and $M$. dictyopora were BLAST searched in GenBank and Mycobank databases and these molecular information appeared to be the first sequences to both species. The evolutionary relationship among them could therefore be established for the first time in this study. So far, almost 40 species of the genus Ceriporia have been described based on morphology, but molecular biological data (ITS and/or LSU sequences) from only 16 species are reported ${ }^{12-14}$. The ITS+LSU dataset including 42 sequences from 28 Ceriporia and 14 other related species comprised 2369 characters alignment with 1601 constant, 212 variable, and 556 parsimony informative sites; tree length was 2561 with $\mathrm{CI}=0.454, \mathrm{RI}=0.616$, and $\mathrm{RCI}=$ 0.280 (Fig. 3). Bayesian analysis based GTR+G model resulted in an average standard deviation of split frequencies $=0.0094$ established identical tree topology as the MP analysis (Fig. 3). The tree topology showed that most of Ceriporia species formed a clade, except $C$. inflata, $C$. mellea, and C. camaresiana which clustered with Phanerochaete species. All morphologically identified Ceriporia species were clustered well within the species level. Although C. cystidiata was clustered as a sister clade with C. lacerata (Fig. 3), the morphological differences between them clearly support their identities.

The BLASTn search results of ITS and LSU 


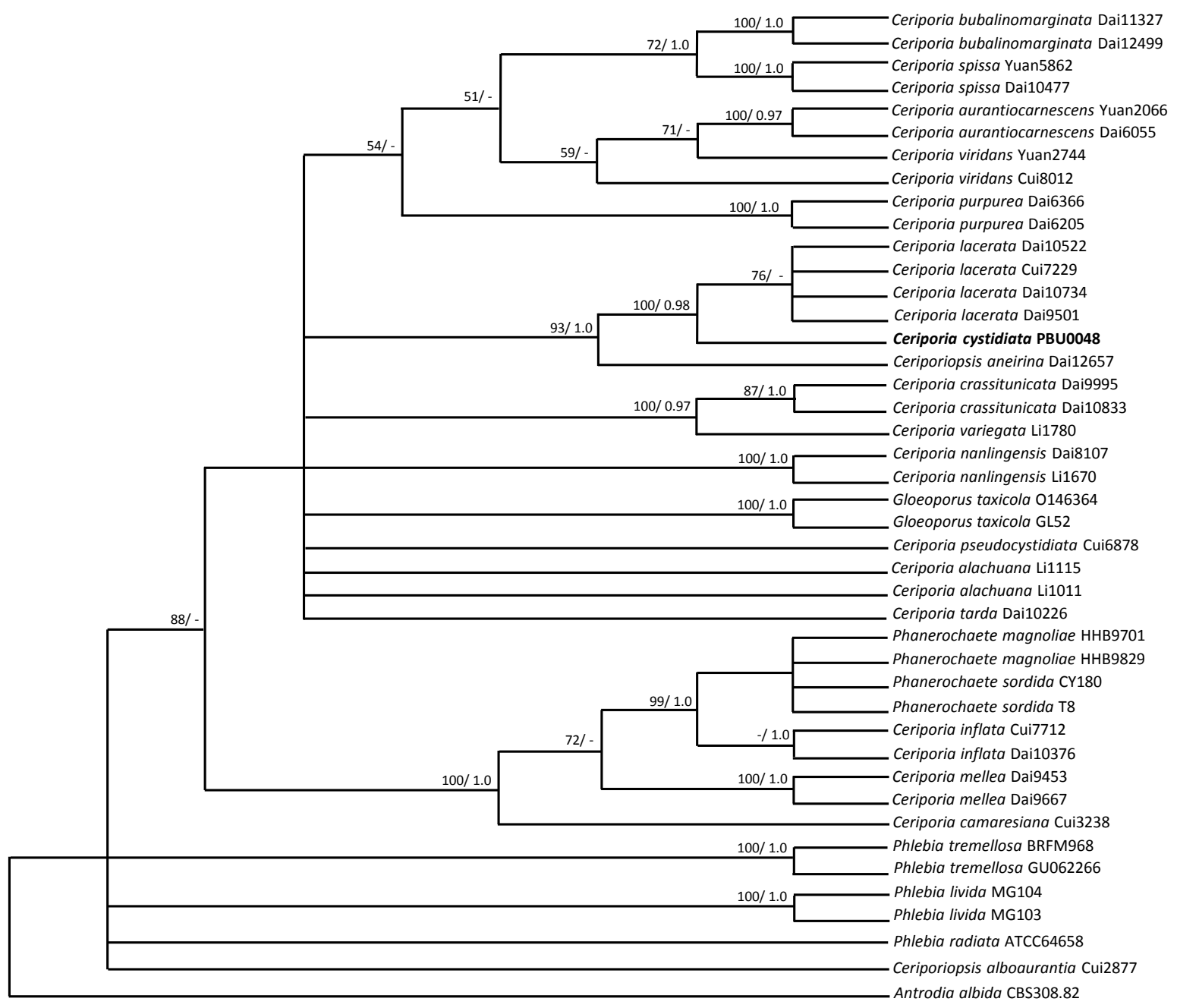

1.0

Fig. 3 Phylogenetic tree of the newly isolated C. cystidiata and its related species based on ITS + LSU sequences from GenBank generated by maximum parsimony method. Antrodia albida is the outgroup. Values labelled above the branches are bootstrap proportions (greater than 50\%) / Bayesian probabilities (greater than 0.95).

sequences from $M$. dictyopora PBU 0051 revealed less than $92 \%$ maximum sequence similarity with the sequences in GenBank and Mycobank databases. The length of aligned dataset is 2288 characters with 1482 constant, 291 variable, and 515 parsimony informative sites; tree length was 1449 steps, $\mathrm{CI}=0.508, \mathrm{RI}=0.333$, and $\mathrm{RCI}=0.169$. Bayesian analysis based GTR $+\mathrm{I}+\mathrm{G}$ model with an average standard deviation of split frequencies $=0.0086$ established similar tree topology as the MP analysis. The phylogeny could establish five major clades of including Antrodia, Core polyporoid, phlebioid, Gelatoporia, and Residual polyporoid clades which is similar to the previous studies ${ }^{3}$. Previous reports described $M$. dictyopora based on morphology with the supposed genus position related to Wolfiporia and Laetiporus groups which were located in Antrodia clade ${ }^{34}$. However, the present phylogenetic analysis revealed that this species is clustered well within phlebioid clade and closely related to C. lacerata and Trametopsis cervina (Fig. 4).

\section{CONCLUSIONS}

Information of tropical resupinate fungi continues to unfold. In this study, the first molecular data for $C$. cystidiata and the genus Macrohyporia were 


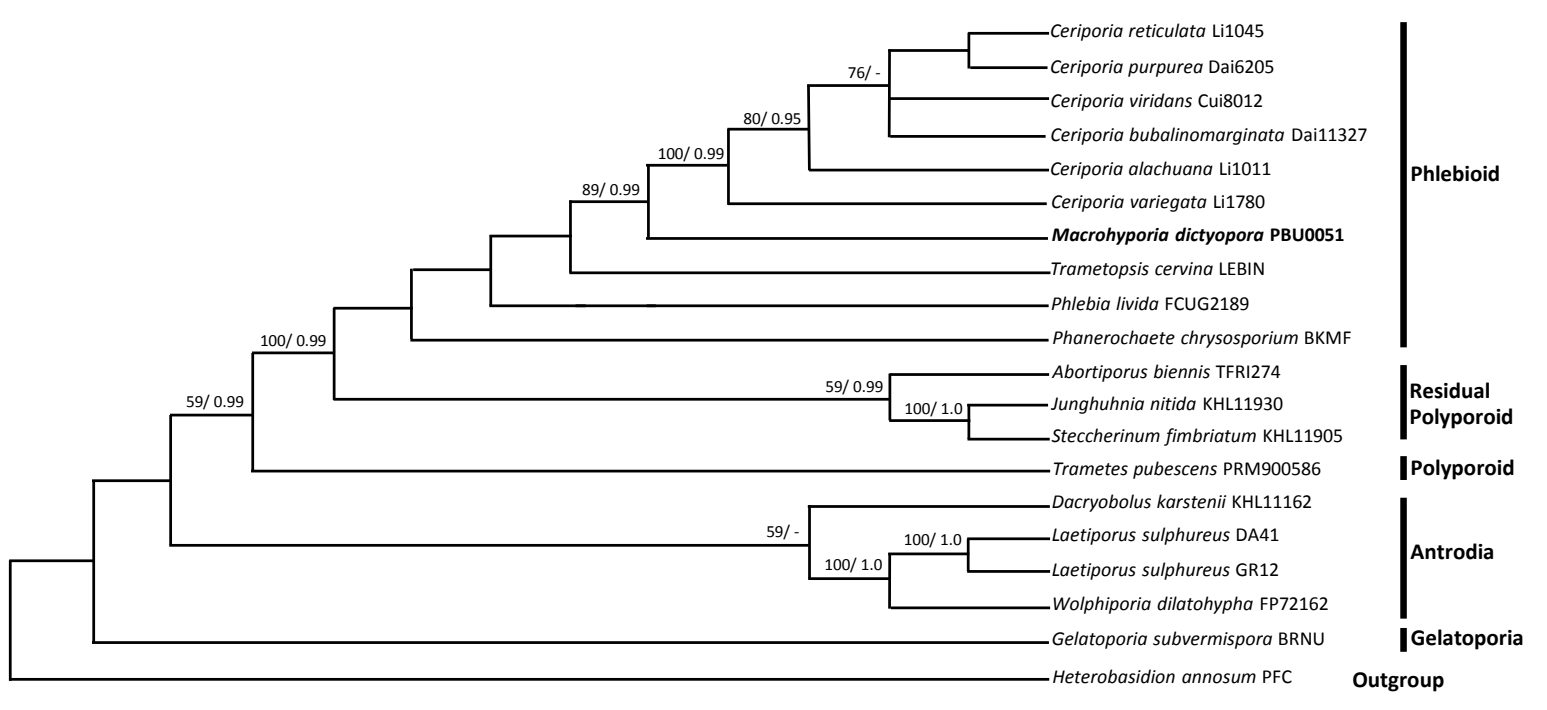

0.04

Fig. 4 Phylogenetic tree of the newly isolated M. dictyopora and its closely related taxa based on ITS + LSU sequences from GenBank generated by maximum parsimony method. Heterobasidion annosum is the outgroup. Values labelled above the branches are bootstrap proportions (greater than 50\%) / Bayesian probabilities (greater than 0.95).

obtained, showing the relationships of $C$. cystidiata within Ceriporia spp. and Macrohyporia genus within polyporoid group, respectively. Further studies are needed to address the taxonomic and systematic status of this complex Polyporales group.

Acknowledgements: The authors thank the Thailand Research Fund/Royal Golden Jubilee Programme (TRF/RGJ; PHD/0162/2549), the Eveleigh-Fenton fund and Japan Society for the Promotion of Science (JSPS), National Research Council of Thailand (NRCT), Vietnam Ministry of Science and Technology (MOST), the National University of Laos, Beuth University of Applied Sciences, and Brawijaya University for financial support; the Department of Plant Biology and Pathology, Rutgers University; the National Museum of Natural Science, Taiwan; and the Plant Biomass Utilization Research Unit and the Biological Science Ph.D. programme, the Department of Botany, Faculty of Science, Chulalongkorn University for providing support and equipment; Ms. Yi Ting Wang and Mr Tomas Allen Rush for providing advice on resupinate fungi identification.

\section{REFERENCES}

1. Kirk PM, Cannon PF, Minter DW, Stalpers JA (2008) Ainsworth \& Bisby's Dictionary of the Fungi, 10th edn, CAB International, Wallingford, UK.

2. Volk T (2000) Polypore primer: An introduction of the characters used to identify poroid wood decay fungi. McIlvainea 14, 74-82.

3. Binder $\mathrm{M}$, Hibbett DS, Larsson $\mathrm{KH}$, Larsson $\mathrm{E}$, Langer E, Langer G (2005) The phylogenetic distribution of resupinate forms across the major clades of mushroom-forming fungi (Homobasidiomycetes). Systemat Biodivers 3, 113-57.

4. Hibbett DS, Binder M, Bischoff JF, Blackwell M, Cannon PF, Eriksson OE, Huhndorf S, James T, et al (2007) A higher-level phylogenetic classification of the Fungi. Mycol Res 111, 509-47.

5. Chen JJ, Cui BK (2014) Phlebiporia bubaline gen. et. sp. nov. (Meruliaceae, Polyporales) from Southwest China with a preliminary phylogeny based on rDNA sequences. Mycol Progr 13, 563-73.

6. Chen JJ, Cui BK, Dai YC (2016) Global diversity and molecular systematics of Wrightoporia s.l. (Russulales, Basidiomycota). Persoonia 37, 21-36.

7. Cui BK, Dai YC (2013) Molecular phylogeny and morphology reveal a new species of Amyloporia (Basidiomycota) from China. Antonie Leeuwenhoek 104, 817-27.

8. Zhao CL, Cui BK, Dai YC (2013) New species and phylogeny of Perenniporia based on morphological and molecular characters. Fungal Divers 58, 47-60.

9. Larsson $\mathrm{KH}$ (2007) Re-thinking the classification of corticioid fungi. Mycol Res 111, 1040-63.

10. Larsson KH, Larsson E, Kõljalg U (2004) High phylogenetic diversity among corticioid homobasidiomycetes. Mycol Res 108, 983-1002.

11. Hjortstam K, Ryvarden L (2007) Checklist of corti- 
cioid fungi (Basidiomycotina) from the tropics, subtropics and the southern hemisphere. In: Synopsis Fungorum vol 22, Fungiflora A/S, Oslo, pp 27-146.

12. Gilbertson RL, Ryvarden L (1987) North American Polypores vol 2, Fungiflora A/S, Oslo.

13. Jia BS, Zhou LW, Cui BK, Rivoire B, Dai YC (2014) Taxonomy and phylogeny of Ceriporia (Polyporales, Basidiomycota) with an emphasis of Chinese collections. Mycol Progr 13, 81-93.

14. Ryvarden L, Iturriaga T (2003) Studies in neotropical polypores 10 . New polypores from Venezuela. $M y$ cologia 95, 1066-77.

15. Donk MA (1933) Revision der Niederländischen Homobasidiomycetae-Aphyllophoraceae II, H Stam, Amsterdam-Haarlem, The Netherlands, [in German].

16. Buchanan PK, Hood IA (1992) New species and new records of Aphyllophorales (Basidiomycetes) from New Zealand. New Zeal J Bot 30, 95-112.

17. Cunningham GH (1965) Polyporaceae of New Zealand, Department of Scientific and Industrial Research Bulletin vol 164, Wellington, New Zealand.

18. Johansen I, Ryvarden L (1979) Studies in the Aphyllophorales of Africa: VII. Some new genera and species in the Polyporaceae. Trans Br Mycol Soc 72, 189-99.

19. Ryvarden L, Johansen I (1980) A Preliminary Polypore Flora of East Africa, Fungiflora A/S, Oslo.

20. Núñez M, Ryvarden L (1999) Studies in neotropical polypores 4 . New and noteworthy species from Coiba National Park, Panama. Mycotaxon 71, 361-8.

21. Chandrasrikul A, et al (2011) Checklist of Mushrooms (Basidiomycetes) in Thailand, Office of Natural Resources and Environmental Policy and Planning, Bangkok, Thailand.

22. Watling $R$ (1998) Thai national forest and nature reserves: Their mycodiversity in relation to surrounding countries. In: Proceedings of the Asia-Pacific Mycological Conference on Biodiversity and Biotechnology, July 6-9, Hua Hin, Thailand.

23. Choeyklin R, Hattori T, Jones EBG (2011) A checklist of aphyllophoraceous fungi in Thailand: Part I. New records. Mycosphere 2, 161-77.

24. Eriksson J, Hjortstam K, Ryvarden L (1984) The Corticiaceae of North Europe vol 5, Fungiflora A/S, Oslo.

25. Wu SH (1990) The Corticiaceae (Basidiomycetes) Subfamilies Phlebioideae, Phanerochaetoideae and Hyphodermoideae in Taiwan, Acta Botanica Fennica vol 142, Finnish Zoological and Botanical Publishing Board, Helsinki.

26. Davis LG, Dibner MD, Battey JF (1986) Preparation of DNA from Eukaryotic cells: General method. In: Davis LG (ed) Basic Methods in Molecular Biology, Elsevier, New York, pp 44-6.

27. White TJ, Bruns T, Lee S, Taylor JW (1990) Amplification and direct sequencing of fungal ribosomal RNA genes for phylogenetics. In: Innis MA, Gelfand DH, Sninsky JJ, White TJ (eds) PCR Protocols: A Guide to Methods and Applications, Academic Press, New York, pp 315-22.

28. Edgar RC (2004) MUSCLE: multiple sequence alignment with high accuracy and high throughput. $\mathrm{Nu}$ cleic Acids Res 32, 1792-7.

29. Tamura K, Stecher G, Peterson D, Filipski A, Kumar S (2013) MEGA6: Molecular evolutionary genetics analysis version 6.0. Mol Biol Evol 30, 2725-9.

30. Swofford DL (2002) PAUP*: Phylogenetic Analysis Using Parsimony (*and Other Methods), version 4.0.b10, Sinauer Associates, Sunderland, MA.

31. Ronquist F, Teslenko M, van der Mark P, Ayres DL, Darling A, Höhna S, Larget B, Liu L, et al (2012) MrBayes 3.2: Efficient Bayesian phylogenetic inference and model choice across a large model space. Syst Biol 61, 539-42.

32. Cooke MC (1888) Australasian fungi. Grevillea 16, 113-4.

33. Lindner DL, Banik MT (2008) Molecular phylogeny of Laetiporus and other brown rot polypore genera in North America. Mycologia 100, 417-30.

34. Ortiz-Santana B, Lindner DL, Miettinen O, Justo A, Hibbett DS (2013) A phylogenetic overview of the antrodia clade (Basidiomycota, Polyporales). Mycologia 105, 1391-411. 